\title{
Design and Build 3d Educational Game "Motorized Millennials" for Indonesian Teenagers
}

\section{Rancang Bangun Game Edukasi 3d "Milenial Bermotor" Bagi Remaja Indonesia}

\author{
Mochammad Iwan Ardiansyah ${ }^{1}$, Cindy Taurusta ${ }^{2}$ \\ Program Studi Informatika, Universitas Muhammadiyah Sidoarjo. Indonesia \\ Iwanardiansyh892@gmail.com ${ }^{1}$,Taurustacindy@gmail.com²
}

\begin{abstract}
Abstract. Traffic signs are one of the things road equipment which consists of symbols, numbers, letters, sentences or a combination of them serves for prohibitions, orders, warnings, and instructions for road users. The younger generation often neglects even many who do not obey the traffic rules, as a result, accidents often occur. From a research Rahmi concluded that $84.5 \%$ of students ride motorbikes to school and get $56.8 \%$ respondents and have criteria for less safe actions in two-wheeled driving and $43.3 \%$ safe criteria including driving while communicating with a mobile phone 51\% (Rahmi, 2009). An innovation that is suitable for Indonesian youth in studying traffic signs is the game method. Because teenagers tend to like to play and learn. so the game method with game media is very suitable to be applied to make it easier for teenagers to learn about traffic signs. Therefore, the purpose of this research is one of them can attract the interest of the younger generation to be able to learn to recognize traffic signs in order to reduce accidents while driving. The data collection methods that we use in this study include: Interviews, Field Observations, Functional Requirements Analysis, System Design, System Testing, Application Testing Design. We have carried out the results of testing this educational game starting from testing all buttons, displaying questions, displaying scores, and displaying every available menu. The results of research that have been carried out are displaying menus in motorized millennial games including: first we install the apk, bring up the application icon, display the game start page starting from: how to play, start and exit.
\end{abstract}

Keywords : Games, Education, Traffic Signs, Teenagers

\begin{abstract}
Abstrak. Rambu lalu lintas merupakan salah satu dari hal-hal perlengkapan jalan raya yang terdiri dari lambang, angka, huruf, kalimat atau perpaduan diantaranya berfungsi untuk larangan, perintah, peringatan, serta petunjuk bagi pemakai jalan raya. Generasi muda sering melaikan bahkan banyak yang tidak menaati peraturan lamubu lalu lintas akibatnya adalah sering terjadi kecelakaan. Dari sebuah penelitian Rahmi menyimpulkan bahwa $84.5 \%$ siswa/i mengendarai sepeda motor ke sekolah serta mendapatkan responden $56.8 \%$ serta memiliki kriteria tindakan kurang aman dalam berkendaraan roda dua dan $43.3 \%$ kriteria aman diantaranya berkendaraan sambil melakukan komunikasi dengan hand phone 51\% (Rahmi, 2009). Inovasi yang cocok untuk renaja Indonesia dalam mempelajari rambu lalu lintas yaitu dengan metode permainan. Karena remaja cenderung suka bermain dan belajar. jadi metode permainan dengan media game sangat cocok diterapkan untuk mempermudah remaja dalam belajar mengenai rambu-rambu lalu lintas. Maka dari itu tujuan penelitian ini yakni salah satunya dapat menarik minat generasi muda untuk dapat belajar mengenal rambu-rambu lalu lintas agar mengurangi kecelakaan didalam berkendara. Metode pengumpulan data yang kami gunakan dalam penelitian ini ada beberapa diantaranya : Wawancara, Observasi Lapangan, Analisis Kebutuhan Fungsional, Perancangan Sistem, Pengujian Sistem, Rancang Pengujian Aplikasi. Hasil pengujian game edukasi ini sudah kami laksanakan mulai dari pengujian semua tombol, menampilkan soal, menampilkan score, dan menampilkan setiap menu yang ada. Hasil penelitian yang sudah dilakukan yakni menampilkan menu didalam game milenial bermotor di antaranya : pertama kita install apk, memunculkan icon aplikasi, tampilan halaman awal game mulai dari : cara bermain, mulai dan keluar.
\end{abstract}

Kata kunci : Game, Edukasi, Rambu-rambu lalu lintas, Remaja 


\section{Pendahuluan}

Sebuah masalah kependudukan akan menjadi sebuah masalah penting bagi pemerintah dan para pakar kependudukan di Indonesia (Sunaryanto, 2012). Sebuah Hasil Sensus Penduduk (SP) tahun 2010 memperlihatkan grafik kenaikan pertumbuhan penduduk Indonesia dari 1,45 persen pada periode 1990-2000 menjadi 1,49 persen pada periode 2000-2010. Penduduk di Indonesia sampai saat ini sebesar 237.641.326 jiwa pada tahun 2010 dan diproyeksikan mencapai 261.890.900 jiwa pada tahun 2017 [1].

Kecelakaan sebuah peristiwa tidak terjadi karena kebetulan. Oleh karena ada penyebabnya, terjadinya kecelakaan harus dianalisis dan ditemukan solusinya, agar tindakan korektif penyebab itu dapat dilakukan dengan upaya diminimalisir lebih lanjut agar kecelakaan dapat dikurangi. Kecelakaan adalah sebuah peristiwa atau tindakan tidak direncanakan dan tidak terkendali, penyebabkan cedera atau kemungkinan cedera [2].

Banyak farktor menyebabkan terjadinya kecelakaan di jalan raya adalah faktor utama penyebab kematian pada usia muda, khususnya laki-laki dan menyebabkan kecacatan fsik. Tingginya angka kematian akibat kecelakaan lalu lintas di usia muda dikarenakan rendahnya pandangan mereka terhadap risiko bahaya yang ada di jalan raya. Pengendara berusia muda sering menempatkan diri mereka pada situasi berbahaya misalnya pada saat mengendarai motor dengan kecepatan tinggi, tidak menggunakan alat keselamatan berupa helm dan sarung tangan, menerobos lampu merah [3].

Sebuah penelitian dari Rahmi memperoleh $84.5 \%$ siswa/i menggunakan sepeda motor ke sekolah dan $56.8 \%$ pengguna memiliki kriteria tindakan tidak aman dalam mengendarai sepeda motor serta $43.3 \%$ kriteria kurang aman pada waktu berkendara sambil melakukan komunikasi dengan hand phone 51\% [4].

Bermula dari masalah itu, maka peneliti memeliki ide sebuah media pembelajaran baru yaitu Game Simulasi yang berjudul "Rancang Bangun Game Edukasi 3D "Milenial Bermotor" Bagi Remaja Indonesia", game ini nantinya berguna untuk membantu generasi milenial yang belum mengetahui rambu - rambu lalu lintas. Game edukasi ini berfokus pada bagaimana mengendarai kendaraan bermotor yang benar dan membantu generasi milenial ini untuk memberitahukan serta memahami rambu lalu lintas. Game berjenis simulasi pembelajaran, untuk game playnya hampir sama dengan game mengendarai kendaraan bermotor lainnya tetapi pada game ini ada peraturan lalu lintas yang harus ditaati pada saat mengendarai kendaraan bermotor. Dimana pengguna nanti akan di sediakan tombol untuk memainkan game ini.[5].

Harapan pada game edukasi ini adalah dapat membantu generasi milenial memahami rambu - rambu lalu lintas agar kecelakaan yang ada di jalan raya semakin hari semakin berkurang.

\section{METODE}

Teknik pengumpulan data yang bertujuan untuk menghasilkan informasi maupun data-data penunjang serta pelengkap teori untuk penelitian adalah sebagai berikut :

1. Wawancara

2. Observasi Lapangan

3. Analisis Kebutuhan Fungsional

4. Perancangan Sistem

5. Pengujian Sistem

6. Rancang Pengujian Aplikasi

Langkah- langkah yang akan dijadikan mengenai teknik diatas bisa melakukan $1-4$ yakni memberikan hasil Flowchart utama untuk di pakai pada penelitian. Berikut ini hasilnya :

\section{A. Flowchart}

Flowchart adalah sebuah teknik analitis yang digunakan untuk menjelaskan aspek-aspek sistem informasi dengan jelas, tepat dan logis [6].

Tampilan flowchart system untuk menjabarkan sebagai sebuah konsep dan alur pendidikan "MILENIAL BERMOTOR" :

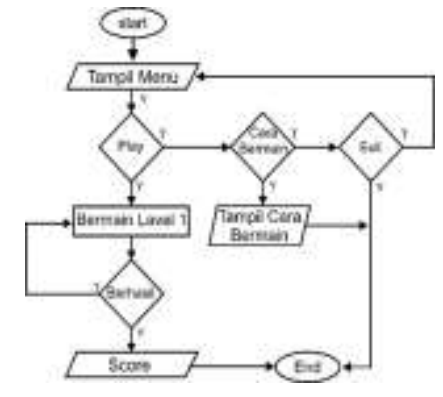

Gambar 1 Flowchart Secara Keseluruhan 
Procedia of Engineering and Life Science Vol. 1. No. 2 Juni 2021

Seminar Nasional \& Call Paper Fakultas Sains dan Teknologi (SENASAINS $2^{\text {nd }}$ )

Universitas Muhammadiyah Sidoarjo

Flowchart diatas dijelaskan bahwa syarat untuk tamat (menang) dari game ini adalah harus menemukan semua rambu-rambu lalu lintas, dan jikalau semua soal sudah terjawab maka player akan memperoleh score akhir.

\section{B. Usecase Diagram}

Use case diagram adalah pemodelan behavior terhadap sistem informasi yang akan dibuat untuk digunakan agar mengetahui fungsi apa saja yang terdapat dalam sistem informasi dan siapa saja berhak menggunakan fungsi tersebut [7]

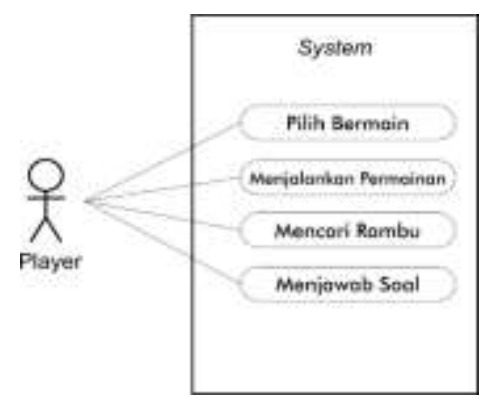

Gambar 2 Usecase Diagram

Dalam usecase diagram diatas adalah player dapat melakukan beberapa pilih diantaranya yakni Pilih bermain, kemudian menjalankan Permainan, mencari rambu jikalau ada keterangan menjawab soal maka player akan menjawab soal tersebut.

\section{Desain Level}

Finite State Machine (FSM) adalah sebuah metodologi perancangan sistem kontrol yang menggabarkan tingkah laku atau prinsip kerja sistem dengan menggunakan tiga hal sebagai berikut: state (keadaan), events (kejadian) dan action (aksi) [9].

Pada game ini memiliki satu desain level yaitu harus menemukan semua rambu - rambu lalu lintas. Dan jika semua rambu - rambu sudah di temukan dan soal sudah terjawab maka secara otomatis game ini menampilkan score akhir yang sudah di peroleh.

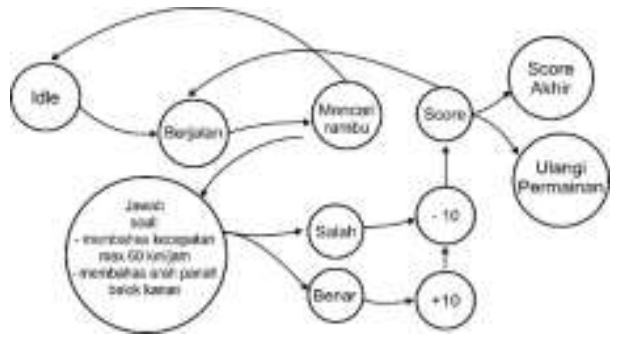

Gambar 3 FSM Level 1

Fsm ini player berjalan sampai menemukan soal kemudian player akan menjawab soal jika jawaban soal benar maka player akan memperoleh score +10 dan jika salah player akan memperoleh score -10 . Apabila sudah menyelesaikan semua rintangan player memperoleh score akhir. Soal yang di suguhkan yakni terkait masalah rambu - rambu lalu lintas.

\section{Alat Serta Bahan Penelitian}

Perangkat Keras

Perangkat keras akan doperlukan dalam penelitian ini berikut meliputi :

1) Laptop Asus X450 Intel ${ }^{\circledR}$ Core $^{\mathrm{TM}}$ i3-3217U CPU @ 1.80GHz (4CPUs).

2) Smartphone Android.

3) SSD $120 \mathrm{~GB}$

4) RAM 2 GB

Perangkat Lunak

Perangkat lunak untuk diperlukan dalam penelitian ini meliputi sebagai berikut:

1) Engine Unity 3D

2) Belender $3 \mathrm{D}$

3) Corel Draw Graphics Suite $X 7$ 


\section{Bahan Penelitian}

1) Pembelajaran rambu-rambu lalu lintas di peroleh Jurnal, Buku serta undang-undang berkendara.

2) Tutorial Tutorial dalam pembuatan game dengan Unity 3D yang diperoleh dari Youtube.

3) Hasil Observasi dan Wawancara dari Guru Kelas X, XI di MA UNGGULAN SINGA PUTIH Prigen Pasuruan.

\section{E. Rencana Pengujian}

Dalam suatu pengujian tersebut akan ada suatu hal-hal pengujian. Berikut ini adalah rencana pengujian :

Unit Testing

Pada pengujian ini digunakan metode whitebox untuk mengetahui uji aspek fungsionalitas terkait softwarenya setiap unit.

Tabel 1 Sebuah Pencapaian pegujian whitebox

\begin{tabular}{|c|c|c|c|c|}
\hline No & Nama & Hasil yang diharapkan & Hasli yang didapatkan & Ketercapaian \\
\hline 1 & Test 1 & Menampilkan pilih menu start & $\begin{array}{l}\text { Menampilkan pilih menu start } \\
\text { tercapai baik }\end{array}$ & Tercapai \\
\hline 2 & Test 2 & $\begin{array}{l}\text { Menampilkan mengendarai } \\
\text { kendaraan bermotor }\end{array}$ & $\begin{array}{l}\text { Menampilkan mengendarai } \\
\text { kendaraan bermotor dengan baik }\end{array}$ & Tercapai \\
\hline 3 & Test 3 & $\begin{array}{l}\text { Menampilkan soal saat } \\
\text { menemui rambu-rambu lalu } \\
\text { lintas }\end{array}$ & $\begin{array}{l}\text { Menampilkan soal menemui } \\
\text { rambu-rambu lalu lintas tercapai } \\
\text { sangat baik }\end{array}$ & Tercapai \\
\hline 4 & Test 4 & Menampilkan scane skor & $\begin{array}{l}\text { Menampilkan scane skor dengan } \\
\text { baik }\end{array}$ & Tercapai \\
\hline
\end{tabular}

Berdasarkan pengujian whitebox akan bisa diketahui sebuah presentase pencapaian fungsionalitas meliputi berikut ini :

$$
\begin{array}{ccc}
\text { Tercapai } & =4 / 4 & \times 100 \%=100 \% \\
\text { Gagal } & =0 / 4 & \times 100 \%=0 \%
\end{array}
$$

\section{Integration testing}

Integration testing merupakan pengujian selanjutnya setelah pengujian unit testing. Dalam pengujian menekankan kepada uji fungsionalitas dan aspek keberhasilan pada saat aplikasi dijalankan. Pengujian integration testing ini menggunakan metode blackbox testing.

\begin{tabular}{|c|c|c|c|c|c|}
\hline No & $\begin{array}{c}\text { Nama } \\
\text { Pengujian }\end{array}$ & Tujuan & Skenario & $\begin{array}{l}\text { Hasil yang } \\
\text { diharapkan }\end{array}$ & Ketercapaian \\
\hline 1 & $\begin{array}{l}\text { Runnging } \\
\text { Aplikasi }\end{array}$ & $\begin{array}{l}\text { Menemukan bugs } \\
\text { yang menyebabkan } \\
\text { aplikasi menjadi } \\
\text { error }\end{array}$ & Menjalankan aplikasi & $\begin{array}{c}\text { Game } \\
\text { berjalan } \\
\text { dengan baik } \\
\text { tidak bugs } \\
\text { dan error }\end{array}$ & Tercapai \\
\hline 2 & $\begin{array}{l}\text { Memilih } \\
\text { Level }\end{array}$ & $\begin{array}{c}\text { Melihat apakah fitur } \\
\text { dan fungsionalitas } \\
\text { button berjalan } \\
\text { dengan baik }\end{array}$ & $\begin{array}{l}\text { Memilih tampilan di menu } \\
\text { awal }\end{array}$ & $\begin{array}{c}\text { Mampu } \\
\text { menjalankan } \\
\text { fungsionalita } \\
\text { s dan } \\
\text { menuju ke } \\
\text { layout yang } \\
\text { sesuai } \\
\text { dengan baik }\end{array}$ & Tercapai \\
\hline 3 & $\begin{array}{c}\text { Menampilk } \\
\text { an petunjuk } \\
\text { permainan }\end{array}$ & $\begin{array}{l}\text { Untuk membantu } \\
\text { user memahami dan } \\
\text { memainkan game } \\
\text { dengan baik }\end{array}$ & $\begin{array}{l}\text { Munculn petunjuk sebelum } \\
\text { memulai permainan }\end{array}$ & $\begin{array}{l}\text { Menampilka } \\
\text { n petunjuk } \\
\text { permainan }\end{array}$ & Tercapai \\
\hline 4. & $\begin{array}{l}\text { Kerakan } \\
\text { karakter } \\
\text { permainan }\end{array}$ & $\begin{array}{l}\text { Supaya user dapat } \\
\text { menggerakkan } \\
\text { karakter pemain }\end{array}$ & $\begin{array}{l}\text { Menggerakkan karakter } \\
\text { pemain dengan cara } \\
\text { menekan tombola arah }\end{array}$ & $\begin{array}{l}\text { Tombol } \\
\text { gerakan } \\
\text { permainan }\end{array}$ & Tercapai \\
\hline
\end{tabular}

Tabel 2 Pencapaian blackbox pegujian 
Procedia of Engineering and Life Science Vol. 1. No. 2 Juni 2021

Seminar Nasional \& Call Paper Fakultas Sains dan Teknologi (SENASAINS 2nd)

Universitas Muhammadiyah Sidoarjo

\begin{tabular}{|c|c|c|c|c|c|}
\hline & & dengan baik & panah & $\begin{array}{c}\text { berfungsi } \\
\text { dengan baik }\end{array}$ & \\
\hline 5. & $\begin{array}{l}\text { Fungsionali } \\
\text { tas tombol } \\
\text { soal }\end{array}$ & $\begin{array}{l}\text { Supaya user dapat } \\
\text { menjawab soal } \\
\text { dengan baik }\end{array}$ & $\begin{array}{l}\text { Memilih soal dengan cara } \\
\text { menekan salah satu soal } \\
\text { yang menurut benar }\end{array}$ & $\begin{array}{l}\text { Tombol soal } \\
\text { berfungsi } \\
\text { dengan baik }\end{array}$ & Tercapai \\
\hline 6. & Score & $\begin{array}{l}\text { Melihat apakah ada } \\
\text { bugs dalam } \\
\text { perhitungan score } \\
\text { pengurangan nyawa }\end{array}$ & $\begin{array}{l}\text { Menyelesaikan semua } \\
\text { pertanyaan tentang rambu- } \\
\text { rambu lalu lintas yang } \\
\text { terdapat di dalam game } \\
\text { tersebut }\end{array}$ & $\begin{array}{c}\text { System } \\
\text { score } \\
\text { berjalan } \\
\text { dengan baik } \\
\text { dan benar }\end{array}$ & Tercapai \\
\hline
\end{tabular}

Berdasarkan pengujian blackbox akan bisa diketahui sebuah presentase pencapaian fungsionalitas meliputi berikut ini:

System Testing

$$
\begin{array}{ccc}
\text { Tercapai } & =6 / 6 & \times 100 \%=100 \% \\
\text { Gagal } & =0 / 6 & \times 100 \%=0 \%
\end{array}
$$

Pada tahap system testing ini pengujian dilakukan dengan menggunakan metode stress testing dalam pengujian stability, reliability, dan compability.

a. Install dan Launch System Testing

Pada tahap ini dilakukan pengujian dengan cara memasang dan menjalankan aplikasi pada beberapa pengakat dengan system operasi yang berbeda dan ukuran layar yang berbeda. Berikut ini adalah rancang hasil pengujian dari aspek compability.

Tabel 3 Hasil pegujian compability

\begin{tabular}{ccc}
\hline Faktor yang diuji & Hasil uji online tool & Hasil uji perangkat \\
\hline Android 8.0 & Sukses & Sukses \\
Android 5.1.1 & Sukses & Sukses \\
\hline $1920 \times 1080$ & Resolusi Layar & \\
$720 \times 1280$ & Sukses & Sukses \\
\hline
\end{tabular}

b. Stress Testing

Pada tahap pengujian ini dilakukan untuk mengetahui apakah ada bugs dan penurunan performa apabila game digunakan berkali-kali. Berikut adalah rancang hasil dari pengujian stress testing yang diujikan:

\begin{tabular}{|c|c|}
\hline Nama Perangkat & Hasil Uji \\
\hline Xiomi Redmi note 5 plus & Tidak ada bugs \\
\hline Xiaomi Redmi Note 8 & Tidak ada bugs \\
\hline Realme 5 Pro & Tidak ada bugs \\
\hline
\end{tabular}

Tabel 4 Hasil Pengujian Stress Testing

Pada tahap pengujian ini end-user agar dapat memastikan apakah aplikasi game kunga ini bisa diterima dan sudah layak digunakan atau belum. Pada tahap ini juga mencari tahu apakah ada permasalahan yang ditemukan pada saat game diujikan kepada user. Tahap ini diujikan dengan menggunakan metode kuisioner yang dibagikan secara acak kepada 15 user yang teridiri dari : 6 Siswa Kelas 2 dan 4 Siswa Kelas 3 dan 3 orang guru dan 2 Ahli Media dengan maple al-qur'an hadis dengan 10 Jenis pertanyaan dan digunakan skala 1-3 dengan skorr maksimal 450.

\begin{tabular}{|c|c|c|c|c|c|c|c|c|c|c|c|}
\hline & \multicolumn{11}{|c|}{ Responden } \\
\hline \multirow{6}{*}{ 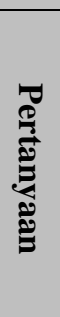 } & & 1 & 2 & 3 & 4 & 5 & 6 & 7 & 8 & 9 & 10 \\
\hline & 1 & 3 & 3 & 3 & 3 & 3 & 3 & 3 & 3 & 3 & 3 \\
\hline & 2 & 3 & 3 & 3 & 3 & 3 & 2 & 3 & 3 & 3 & 3 \\
\hline & 3 & 3 & 3 & 3 & 3 & 3 & 3 & 3 & 2 & 3 & 3 \\
\hline & 4 & 3 & 3 & 3 & 3 & 3 & 3 & 3 & 3 & 3 & 3 \\
\hline & 5 & 3 & 3 & 3 & 3 & 3 & 3 & 3 & 3 & 3 & 3 \\
\hline
\end{tabular}

Tabel 5 Hasil Kuisioner Anak-Anak SMA 
Procedia of Engineering and Life Science Vol. 1. No. 2 Juni 2021

Seminar Nasional \& Call Paper Fakultas Sains dan Teknologi (SENASAINS 2nd)

Universitas Muhammadiyah Sidoarjo

\begin{tabular}{|c|c|c|c|c|c|c|c|c|c|c|c|}
\hline & 6 & 3 & 2 & 3 & 3 & 3 & 3 & 3 & 3 & 3 & 2 \\
\cline { 2 - 11 } & 7 & 3 & 3 & 3 & 3 & 3 & 3 & 2 & 3 & 3 & 2 \\
\hline & 8 & 2 & 3 & 2 & 3 & 2 & 3 & 3 & 3 & 3 & 3 \\
\hline & 9 & 3 & 3 & 3 & 3 & 3 & 3 & 3 & 2 & 3 & 3 \\
\hline & 10 & 3 & 3 & 3 & 3 & 3 & 3 & 2 & 3 & 3 & 3 \\
\hline Jumlah & 29 & 29 & 29 & 30 & 29 & 29 & 28 & 28 & 30 & 28 \\
\hline
\end{tabular}

Dari semua hasil pengujian yang telah dilakukan dapat digunakan untuk mengetahui hasil dari ketercapaian aplikasi yang sudah dibuat dan disimpulkan menjadi seperti berikut :

Tabel 6 Kesimpulan Hasil Pengujian dari 4 Aspek yang Telah Diuji

\begin{tabular}{|c|c|c|c|c|}
\hline No & Aspek Pengujian & Tahap Pengujian & Presentase & $\begin{array}{c}\text { Tingkat } \\
\text { Kelayakan }\end{array}$ \\
\hline 1 & Functionality & Unit Testing & $100 \%$ & Sangat Baik \\
\hline 2 & Functionality & Integration Testing & $100 \%$ & Sangat Baik \\
\hline 3 & Reability & System Testing & $100 \%$ & Sangat Baik \\
\hline 4 & Compability & System Testing & $100 \%$ & Sangat Baik \\
\hline 5 & Playability & Acceptance Testing & $96 \%$ & Sangat Baik \\
\hline
\end{tabular}

Dari table diatas digunakan analisis likert untuk merubah data tersebut menjadi data kualitatif. Sehingga didapatkan rata-rata seperti berikut :

$$
\begin{array}{llrl}
\text { Rata-rata } & =\frac{\text { Jumlah Nilai }}{\text { Banyak Nilai }} & \text { x } 100 \% & \\
\text { Rata-rata } & =\frac{436}{450} & \times 100 \%=96 \%
\end{array}
$$

\section{Hasil dan Pembahasan}

\section{A. Tahap Pelaksanaan}

Setelah melewati sebuah analisa serta penggambaran system game pada bab sebelumnya untuk itu selanjutnya yaitu hasil dan pembahasan pada game atau alur kerja pada game tersebut. Adapaun proses pembangunan game dirancang mengetahui sebuah hasil proses analisa serta perancangan untuk game yang sudah diimplemetasika pada bab sebelumnya, hasil dapat diperoleh berikut ini:

\section{B. Pembahasan}

\section{Tampilan Utama Game}

Dalam tahapan implementasi ini, penelitian ini dilakukan untuk penerapan game dari segi serta fungsi sudah mencapai gambaran dan tujuan untuk ditentukan suatu pembuatan game Milenial Bermotor. Dalam penerapan ini menghasilkan sebuah gambaran suatu aspek akan menjadi sebuah kekurangan serta kelebihan untuk sebuah aplikasi game tersebut sudah dibuat.

Tampilan Scene Halaman Awal

Pada Halaman yakni Halaman Menu Utama pengguna game ini disuguhkan 3 tombol Buttom yakni Tombol cara bermain, tombol Play dan Quick.

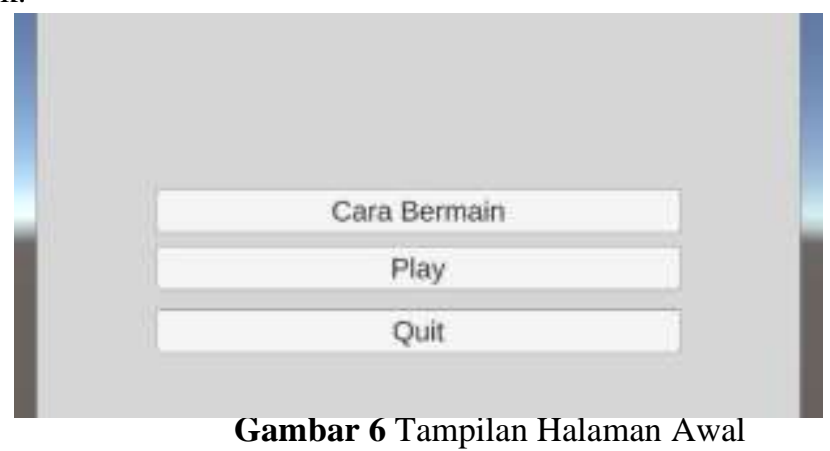

Tampilan Scene Mengendarai Kendaraan Bermotor

Pada halaman ini ada player disuguhkan beberapa tampilan mulai tombol buttom gas, buttom belok kiri dan kanan, buttom pause dan notifikasi score. 


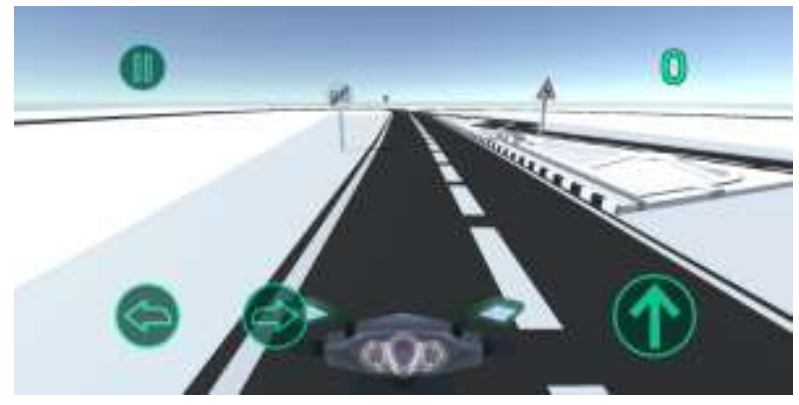

Gambar 7 Tampilan Mengendarai Kendaraan Bermotor

\section{Tampilan Scene Soal}

Berikut adalah menampilkan soal dari game ini. Pada tampilan ini player di wajibkan untuk menjawab soal jikalau menjawab soalnya benar maka mendapatkan point 10 jikalau player menjawab soalnya salah maka point dikurangi 10.berikut ini soal yang akan di jawab :

Soal ini membahas kecepatan maksimal $60 \mathrm{~km} / \mathrm{jam}$

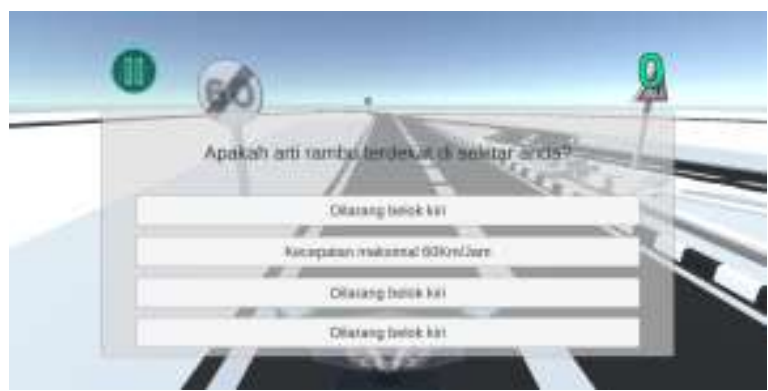

Gambar 8 Tampilan Soal kecepatan maksimal 60 km/jam

Tampilan Scene Skor

Pada halaman ini adalah halaman skor total yang di peroleh dari permaianannya. Nilai secara otomoatis keluar setelah menyelesaikan permainnya. Di halaman ini ada dua tombol buttom yang pertama Restart dan Quit. Untuk tommbol Buttom Restart ini digunakan untuk mengulangi permainannya dan untuk tombol Quit adalah tombol mengakhiri permainan ini.

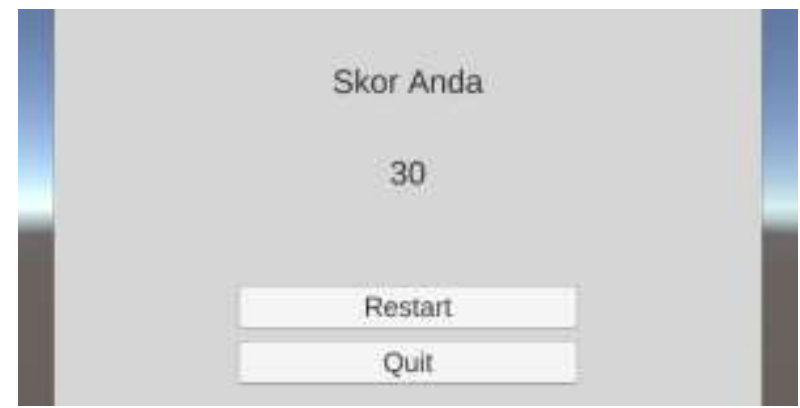

Gambar 13 Tampilan Skor

\section{KESIMPULAN}

Sebuah hasil dalam penelitian sudah diterapkan ke pengujian milenial bermotor ini dapat disimpulan, bahwa game melenial bermotor ini dapat menarik minat generasi muda untuk dapat belajar mengenal rambu-rambu lalu lintas. Pada game milenial bermotor ini belajar rambu - rambu lalu lintas jadi lebih bisa mengerti dan dipahami dan dengan game milenial bermotor ini mengenal rambu - rambu lalu lintas jadi lebih menyenangkan. Dalam proses pembelajaran siswa lebih senang belajar dan bermain. Untuk rancangan game edukasi kunga ini melalui metode ADDIE (Analisis, Design, Developer, Implementation, dan Evaluation). Pada tahan analisis masalah ditemukan bahwa siswa SMA mengalamai kesulitan dalam mempelajari rambu - rambu lalu lintas. 


\section{UCAPAN TERIMA KASIH}

Dalam penyusunan skripsi ini, ternyata tidak lepas dari bantuan dan dorongan semua pihak. Untuk itu tidak lupa saya ucapkan banyak terimakasih kepada semua pihak yang telah membantu menyelesaikan skripsi ini :

1. Bu Cindy Taurusta, S.ST., M.T, selaku Dosen Pembimbing yang telah memberikan bimbingan, arahan, dan dukungan sehingga skripsi ini dapat terselesaikan dengan baik.

2. Bapak/Ibu dosen serta staf di lingkungan Univesitas Muhammadiyah Sidoarjo yang telah banyak membantu penulis selama mengikuti perkuliahan dan penulisan skripsi ini.

3. Kedua Orang Tua saya yang selalu memberi dorongan motivasi dan do'a.

4. Rekan-Rekan Informatika Universitas Muhammadiyah Sidoarjo yang memberikan banyak dukungan.

\section{REFERENSI}

[1] Sulastiningsih, Febri., \& Karnoto, R. (2018) Smart Riders 3D Sebagai Game pengenalan rambu lalu lintas Berbasis Android, Jurnal. Universitas Negri Semarang

[2] Undang-Undang Nomor 13 tahun 2014 tentang Rambu Lalu Lintas

[3] Kusminingrum, N., \& Gunawan, G. (2008). Polusi udara akibat aktivitas kendaraan bermotor di jalan perkotaan Pulau Jawa dan Bali. Jurnal, Jakarta, Puslitbang Jalan dan Jembatan. BLACK BOX TESTING BOUNDARY VALUE ANALYSIS, I(3), 31-36.

[5] Andriyanto, Irawan (2016) Game edukai pengenalan rambu-rambu lalu lintas untuk anak SD, Skripsi. Universitas Muhammadiyah Surakarta

[6] Wulandari, fitri. (2015) Pemahaman Pelajar Tentang Disiplin Berlalu Lintas. Jurnal sosiologi vol 3 no 3

[7] S. Muyaroah dan M. Fajartia, "Pengembangan MediaPembelajaran Berbasis Android dengan menggunakan Aplikasi Adobe Flash CS 6 pada Mata Pelajaran Biologi Abstrak", Innov. J. Curric. Educ. Technol., vol. 6, no. 2, pp. 79-83, 2017

[8] D. W. Putra, A. P. Nugroho, dan E. W. Puspitarini, "Game Edukasi Sebagai Media Pembelajaran Pendidikan Anak Usia Dini”, Inform, vol. 1, no. 1, pp. 1-8, 2016.

[9] Sholekha, Ikrar Amalia., Arwani, Issa., \& Afrianto, Tri (2018), "Pengembangan Gane Edukasi Ayo Belajar rambu-rambu lalu lintas berbasis Kinect. Jurnal. Universitas Brawijaya.

[10] F. Wulandari, "Pemahaman Pelajar Tentang DisiplinBerlalu Lintas (Studi di SMK Kesehatan)", ejournal Sosiatri - Sosiol., vol. 3, no. 3, pp. 52-64, 2015

[11] Rahman, R. A., \& Tresnawati, D. (2014). PENGEMBANGAN GAME EDUKASI, 184-190. 